Toren, Christina. In press for 2011. 'Anthropology and Psychology'. In Handbook of the Association of Social Anthropologists. Eds: Richard Fardon, John Gledhill, Trevor Marchand, Mark Nuttall, Cris Shore, Marilyn Strathern. London, New York: Sage Publications.

christina.toren@st-andrews.ac.uk 


\section{Anthropology and Psychology}

Christina Toren, University of St Andrews

Anthropologists who work at the interface of psychology and anthropology are by and large committed to anthropology as science. The problem for us, however, is that the institutional development of the human sciences in the late $19^{\text {th }}$ and early $20^{\text {th }}$ centuries effectively allotted different aspects of what it is to be human to different disciplines. Faced with separate epistemological domains of anthropology, psychology, sociology, linguistics, philosophy and biology, scientists in the latter half of the $20^{\text {th }}$ century found themselves having to work hard to put the pieces back together again - body and mind, for example. As is often the case, however, new subdisciplinary domains intended to overcome conceptual difficulties served rather to entrench them. The 1970s saw the invention of psychological anthropology, the 1980s brought us cultural psychology, in the 1990s we re-discovered the body and phenomenology, and at the same time witnessed the resurgence of cognitive anthropology which, during the first decade of the $21^{\text {st }}$ century would appear to dominate the field, contributing to the development of what is today called cognitive science. Whether, over coming decades, cognitive anthropology will continue to dominate our understanding of mind will have everything to do with the extent to which anthropology as an intellectual project is able to realise and come to grips with the real political implications of the ahistorical concept of human being that lies at its heart.

The argument put forward in the present chapter is explicitly opposed to cognitivist models because of their inability to come to grips with human historical actuality in general and their own historical nature in particular. Thus, for all the often 
fascinating work that has been done in the various sub-fields of anthropology, and despite the explosion of knowledge in other subdisciplinary domains - neurobiology and neuroscience, for example - the interface between Anthropology and Psychology at the end of the first decade of the $21^{\text {st }}$ century continues to throw into relief a question that remains fundamental to the human sciences, including anthropology: How are we to conceive of human beings? The answer we give to this question is important because it structures not only what we currently know about ourselves and others, but what we are capable of finding out.

As will become apparent, the recognition of our historical nature provides for a resolution of debates concerning the relative validity of representational, social constructivist and neurophenomenological models of mind. This chapter proposes a unified model of human being whose manifold aspects remain entirely open to investigation, even while the model is intended to deal at once with the uniqueness that is to say, the historical actuality - of what it is to be human and with critical issues at the interface of psychology and anthropology and, in so doing, prove to be a rigorous, explanatory, robust model of what it is to be human.

\section{A unified model of human being}

What are the crucial aspects of such a model? Fundamentally, that its object be conceived of at the outset as living and as human, not as an information processing device. This model starts with human physical actuality: the fact that each one of us is, like other living things, biologically speaking autopoietic - self-creating, selfregulating. A new-born baby, infant or young child requires other humans to look after its primary needs, making its ontogeny a social process. Indeed, as living systems that are human, each and every one of us needs others if we are to maintain 
our autonomy over the course of our own lives and contribute to the lives of others. There is nothing paradoxical about this. Rather it is given to us as human beings that the particular nature of our autonomy resides precisely in the history of our relations with one another. Or to put it another way, our uniqueness in every single case is given in the fact that each one of us has a personal history that makes us who we are.

A propensity for making sense of the environing world is a crucial aspect human being. It follows that 'making sense' (or, in other words, learning) is a dynamic, spatiotemporal process that at any given point inevitably locates humans historically in relation to particular others in particular places at particular times in the peopled world. Or to put it another way, any given human is, in every aspect of his or her being, the dynamic transforming product of the past he or she has lived and is, at any given time, placed in relation to all those others (young and old, living and dead) whose ideas and practices are contributing to structure the conditions of his or her present existence. 'Any given human' here means any foetus, neonate, infant, child, adolescent, adult or old person, because autopoiesis is a process that begins at conception and ends only with death. We can think of ourselves, therefore, as living and manifesting the historical processes that engage us in literally every aspect of our being. For example, whether we consider the matter statistically in population terms, or personally, our physical make-up is the dynamic product of a particular bio-social history which, for all its possible complications and convolutions, could in principle be traced back over many generations. Likewise the language(s) we speak. Likewise our ideas of what is, or could be, in the world and our means for finding out. This personal history is continuous with our evolutionary species history.

In the unified model, mind is a function not of the brain, nor of the embodied nervous system, but of the whole human being in intersubjective relations with others 
in the environing world. Implicit is a view of consciousness as an aspect of human autopoiesis. Here consciousness cannot be a 'domain' or a 'level of psychological functioning', rather it is that aspect of mind that posits the existence of the thinker and the conceptual self-evidentiality of world as lived by the thinker. Intersubjectivity is shorthand for: I know that you are another human like me, and so I know that you know that because I am human, I know that you are too. It is this capacity for recursive thought that makes human learning (here intended in its broadest sense) a microhistorical process. Our intersubjective relationship to one another is always bound to be historically prior because, whenever we encounter one another, we do so as carriers of our own, always unique, history. I make sense of what you are doing and saying in terms of what I already know: any and all experience is assimilated to my existing structures of knowing. This goes for everyone - new born babies and geriatric patients included. Making sense of the peopled world is a material, selforganising process that at once transforms new experience in the course of its assimilation (and to this extent conserves what I already know) and transforms my existing structures of knowing in the course of their accommodation to new experience (and to this extent changes what I know).

In this view, the human being whose ideas and practices we are trying to understand and explain is social through and through and the world of people and things that this human inhabits crucially informs his or her entire constitution, specifically the continuing constitution over time of those processes we call 'mind'. It follows that there is no aspect of anyone's humanity that is not historically constituted. At any given time, when one acts on the world in any way at all, one's 
understanding of the world, oneself and one's relations with other humans, are all informed by one's previous history - that is to say, one's history up to that moment. ${ }^{1}$

The unified model takes for granted that intersubjectivity is emotional, that perceiving and feeling are aspects of one another, and that intentionality is given in an openness towards, and a felt engagement in, the peopled world. ${ }^{2}$ Here learning and teaching are aspects of the selfsame process. ${ }^{3}$ Throughout our lives, our active engagement in the world of people and things effects continuing differentiation of the processes through which we know what we know. The processes of mind are subject as much to change as to continuity, but as we grow older they become progressively less subject to radical change precisely because they are already highly developed. The longer they have been functioning to assimilate information, the more highly differentiated they already are, the less radically they can transform as a function of accommodation to new situations. Thus the unified model bears on humans as living.

Understanding our biological substance is crucial to understanding not only our physical, but our psychological makeup; it makes a difference whether the

\footnotetext{
${ }^{1}$ My first formulation of this model (Toren 1999: 1-21 and 2002) was derived from a synthesis of the works of Maturana and Varela on autopoiesis; Piaget on genetic epistemology, especially his idea of the cognitive scheme as a 'self-regulating transformational system' (i.e., as an autopoietic process); Husserl's and Merleau-Ponty's phenomenology; and certain of Vygotsky's insights on language acquisition. My model has a good deal in common with Thompson (2009) and finds new support in his ground-breaking neurophenomenology and in Tomasello's (2003) work on the ontogeny of language. ${ }^{2} \mathrm{Cf}$ Damasio 1999 who argues that emotion is fundamental both to the organism's survival and to consciousness.

${ }^{3}$ Csibra and Gergely (2006:249) argue that 'human pedagogy [is] an evolutionary adaptation for efficient knowledge transfer', but if, for humans, living is knowing and vice versa, and if living and knowing are historical processes, then the idea of pedagogy as a 'dedicated cognitive system' is unnecessary. Which is not to say that our various ideas of pedagogy are not important for what we know about the world and how we know it. See Ingold (2007) for a related argument from the perspective of 'the social child'.
} 
phenomena of mind are conceived of as neuorophenomenological processes or as computational programmes. More of this below; for the moment it is important just to realise that however sophisticated a computer may be, it does not bring itself into being by virtue of differentiation over time of its own physical substance. Our present knowledge of course leaves a great deal to be desired, but even so we understand enough of autopoiesis as a biological process to realise that logically it has to be applied not only to the physiological dimension of human being, but also to those processes we call mind.

\section{The problem with cultural models}

The processes through which we know the peopled world, like the neurological processes of which they are an aspect, are likewise autopoietic, characterised by continuing differentiation through functioning. Once we understand this, it becomes obvious that information-processing (or representational) models of mind cannot capture its inherent dynamics. Take, for example, schema theory as found in various forms in cognitive anthropology. The idea of the schema-as-mental-representation took hold in cognitive anthropology in the 1980s and was incorporated in the 1990s into connectionist 'neural network' models of psychological functioning. Connectionist models of mind attempt to make computational theory consistent with what we know of the workings of the human brain; they employ an idea of parallel distributed processing that allows for a cognitive scheme that is always emergent, never quite fixed and thus provide for a model of how cognitive processes respond to their own environment and are modified by it. Nevertheless, as representation and as a component of the more complexly configured 'cultural model', the schema that figures in works by Holland and Quinn, D'Andrade and Shore (to take several well- 
known examples) is peculiarly static. ${ }^{4}$ Shore's attempt to distinguish between 'conventional models' and 'personal models' manifests neatly the problem with the schema-as-representation idea of mental processes. Because the schemas that compose cultural models are conceived of as mirroring mental representations of the world inside the human head, Shore's 'cultural model' cannot intrinsically allow for the fact that in so far as we understand and embrace what is conventional, we do so as particular persons with particular histories. From which it follows that for any one of us the conventional and the personal are bound to be aspects of one another (an artefact of the selfsame process) and that continuity over time is likewise an aspect of transformation. ${ }^{5}$

If this idea of continuity-in-transformation sounds odd, just try thinking about yourself - your whole person, including your ideas about the world - as a dynamic system of transformations; aging, for example, is one aspect of the workings of this dynamic system, and so is digestion, and so is reading a book, or having a conversation. You remain autonomously yourself even though, from moment to moment and year to year, your continuity through time is that of a dynamically transforming system.

The problem with a representational model of mind that mirrors objectively given properties of the world did not go away with the development in the 1990s of cultural psychology. Shweder, however, did his best to move anthropologists away from what he characterised as the 'Platonic impulse' that presumed mind to be a fixed

\footnotetext{
${ }^{4}$ See D'Andrade 1995, chapters 6 and 7, and Shore 1996, chapter 2. D'Andrade provides a succinct account of the difference between a connnectionist model and a serial symbolic processing model. ${ }^{5} \mathrm{Cf}$. Piaget's biologically founded idea of the cognitive scheme as a 'self-regulating transformational system' which he explicitly likened to mathematical and logical structures and also to 'structures ... whose transformations unfold in time' (1971:15).
} 
and universal property of the psyche. He argued for a cultural psychology that presumes instead

'that the life of the psyche is the life of intentional persons, responding to, and directing their action at, their own mental objects or representations and undergoing transformation through participation in an evolving intentional world that is the product of the mental representations that make it up' (ibid 1991:97).

He found support both in the idea that 'the mind is embodied in concrete representations, in "mediating schemata," "scripts," and well-practiced "tools for thought"" (ibid: 98) and, of course, in the idea of culture, which he characterised as 'that part of the scheme that is inherited or received from the past' (ibid:101). The problem is that the implicit distinction between culture and biology and the representational information-processing model of mind on which Shweder's account depends render his project incoherent, internally contradictory and unrealisable. ${ }^{6}$ Like other theories of this kind it has recourse to social construction in an attempt to explain the differences between intentional worlds, specifically for example between American and Indian ideas of the person. But social construction itself depends on a historically constituted idea of the person as an individual in society who interacts with other individuals to negotiate their respective ideas about an objectively given world.

The "constructive" parts of a social construction theory are the idea that equally rational, competent, and informed observers are, in some sense, free ... to constitute for themselves different realities; and ... that there are as many realities as the way "it"

\footnotetext{
${ }^{6}$ Take, for example, the following: '... according to the premises of cultural psychology, even the transcendent realities portrayed by scientists are part of intentional worlds and cannot really take us beyond our mental representations of things. In the world of cultural psychology transcendence and self-transformation are possible but only through a dialectical process of moving from one intentional world into the next, or by changing one intentional world into another' (Shweder 1991:99).
} 
can be constituted or described... The "social" parts of a social construction theory are the idea that categories are vicariously received, not individually invented; and [are]... transmitted, communicated and "passed on" through symbolic action (Shweder 1991:156).

In locating the constructive process in the person and what is social in an abstract space between persons (i.e. in language categories for example) social constructionists reproduce the very theoretical impasse they seek to dismantle. ${ }^{7}$ In the absence of an understanding that making sense of the peopled world is an historical process, Shweder cannot render analytical the categories he seeks to understand.

'Cultural construction' of course fares no better, theoretically speaking. The idea that much (if not most) of what humans say and do is the product of cultural construction is a truism of contemporary cultural anthropology. ${ }^{8}$ Culture continues to be taken for granted as explanatory, even though such analytical distinctions as culture-biology, society-individual, mind-body, structure-process, and emotionrationality have long posed problems, especially for psychological anthropologists. ${ }^{9}$ Ideas of cultural construction rest on the same problematic Cartesian distinctions as computational models of cultural meaning. ${ }^{10}$ The ubiquity of the terms is such that I can find even in my own earlier work a number of appearances of 'cultural' and 'construction' and even 'cultural constructs'. But it is not 'construction' that bothers

7 See, e.g., Nussbaum 2001 and compare Hacking 1999.

${ }^{8}$ I first came across the idea in the domain of academic psychology in respect of children (see Kessen 1983). Cultural construction is also central to the development of the contemporary sociology of childhood, where it is inflected by an idea that the child's agency challenges the discourses that constitute particular ideas concerning what a child is (James, Jenks and Prout 1998).

${ }^{9}$ See, for example, Schwartz and colleagues (1992).

${ }^{10}$ See for example Strauss and Quinn, 1997, Part II. Compare attempts to use the insights of phenomenology to analyze embodied mind: here the body is 'the existential ground of culture', which at once manifests and constitutes mind (e.g., Csordas 1990); culture, however, remains taken for granted. 
me so much, it is 'culture' that is analytically empty. ${ }^{11}$ As what is relative and historically specific, culture inevitably implies its counterpart, biology, as the domain of the irreducible, the universal. The analytical poverty of this distinction becomes especially apparent when we turn our attention to anthropological studies where the focus is on children.

\section{Innate modularity vs neuroconstructive development}

Anthropology's objective is to explain the extraordinary multiplicity that is human being in the world or, more exactly, how the uniqueness that is peculiar to every one of us is located in what we have in common. Does it make sense then to think of a neonate as an organism that is born biological only to become cultural as a result of actions performed on it by its caregivers? Surely not, for even in this perspective the infant's capacity to become the carrier of culture is inherent to it; thus culture has to be in some sense given if its particular forms are to be achieved. But if our capacity for culture is biologically given and if all biological ideas are just as much historical artefacts as any other idea, it follows that the biological and the cultural are aspects of one another. So why retain the distinction at all?

We cannot yet track the precise co-ontogeny of neurological processes and conceptual processes, though there are, for example, studies in the developing field of

\footnotetext{
${ }^{11}$ My own attempts to theorise construction have involved, firstly, using Piaget's ideas to render Bourdieu's notion of habitus psychologically viable and capable of incorporating history (see Toren 1990). Later I found it more satisfactory to do away altogether with the over-systematised and paradoxically static habitus and to put forward the theoretical synthesis outlined in Toren 1999 and 2002.The unified model presented in this chapter is the most recent development of this model.
} 
neurophenomenology that are relevant. ${ }^{12}$ What we can do, with some fair degree of validity, is theorise the process in which ideas are constituted over time - their ontogeny from birth onwards. As we shall see below, how we characterise ontogeny is crucial to our understanding of the historical specificity of what it is to be human at any time, in any place.

From birth, babies are immersed in relations with caregivers; indeed newborn babies show capacities which have the effect of facilitating social relationships and which, through functioning, become ever more highly differentiated or in other words, developed. Not all the early capacities of infants implicate social relations, but even so, the very high salience of other humans for babies is apparent. Thus, over the past two decades or so, we have come to know that newborn babies prefer face-like stimuli to other attractive visual stimuli; can discriminate and imitate certain facial gestures of others; show categorical perception of speech sounds; discriminate between curved and straight geometrical shapes; discriminate linguistic input from other auditory inputs and at four days have learned enough to differentiate their native language from others. At three months they show surprise if two solid objects seem to occupy the same space; at four months they show surprise if a solid object seems to have passed through a solid surface; at this age they also show complex cross-modal perception matching speech sounds to lip movements on the faces that produce them. At six months they show talker normalization - recognising as equivalent different speech sounds from different talkers; they are also able to make matches in numerosity between sounds and sights (examples drawn more or less verbatim from Elman et al

\footnotetext{
12 See Lewis (2000 and 2005) for a dynamic systems approach that links emotion theory and neurobiology and Thompson (2007) for suggestions as to an experimental neurophenomenology of time-consciousness.
} 
1996:107). 'By six months, infants follow people's gaze and attend to objects on which people have acted. By nine months, infants reproduce other people's actions on objects, and they communicate about objects with gestures such as pointing' (Spelke pp 402-404). ${ }^{13}$

These demonstrable abilities of neonates and infants have given rise to the idea, now apparently taken for granted by cognitivists of various persuasions, that mind is innately modular - made up of a set of cognitive systems that evolved to deal with separate domains of our environment and that, consequently, all humans have in common.

Cognitive science is a catch-all that takes in congruent models from a number of sub-disciplinary domains - principally evolutionary psychology, cognitive anthropology, neuroscience, and cognitive and developmental psychology. What they have in common is a reliance on analytical distinctions between biology and culture and, for many if not most, the idea that mind is modular. The modularity idea was first proposed by Fodor who argued for a limited number of innate perceptual and linguistic input systems whose outputs fed into central cognitive systems which functioned to integrate the information into more complex, problem-solving, forms of central cognition. ${ }^{14}$ The input-system-as-cognitive-module idea was taken up and

\footnotetext{
${ }^{13}$ The infant's ability at four days to recognise its mother's face seems to be based in the differentiation of 'a general pattern processing system, rather than a face-specific one' (Karmiloff-Smith1995:1298); see Elman et al 1996: 115-118 for the ontogeny of facial recognition.

14 '..all the cases of massive neural structuring to which a content-specific cognitive function can confidently be assigned appear to be associated with language or with perception. ... the key to modularity is informational encapsulation ... hardwired connections indicate privileged paths of informational access (Fodor 1983:98, see also Fodor 1988). Cole suggests that the origin of modularity came out of the debate between Chomsky, Piaget and others concerning what came to be known as the 'language acquisition device' or 'language module' (Cole 1996:198).
} 
elaborated by evolutionary psychologists Tooby and Cosmides (1992) whose 'massive modularity' model became foundational for anthropologists Sperber (1994, 1996) and Hirschfeld (1994), among others. In the 'massively modular' model, mind is made up of cognitive systems that are 'pre-wired' (that is to say, innate) and domain-specific; only a sub-set of them have to do with so-called 'social cognition'. Note however that " $[t]$ he domain of a module is ... not a property of its internal structure (whether described in neurological or in computational terms) ....' but of the 'mode of construal' for which the internal structure provides (Sperber 1996: 135-136). A given mode of construal may be brought to bear on entirely novel conditions of the environment, provided they are amenable, as it were, to being so-construed. Sperber finds support from evolutionary psychologists to argue that 'a cognitive module is an evolved mechanism with a distinct phylogenetic history' (Sperber 1996:124). ${ }^{15}$ Massive modularity underwrites Sperber's information-processing model of brain function and provides for his idea of 'an epidemiology of representations' as the key to understanding culture (Sperber 2006).

This argument has a bearing on the extensive literature that offers us cognitive explanations of religious beliefs. The module-as mode-of -construal idea provides, for example, for the way that modularity theory may be used to explain religion as the inevitable projection of human consciousness into cosmological ideas concerning an

\footnotetext{
15 The reader should be aware of the difference between evolutionary psychology and evolutionary biology. Mesoudi, Whiten and Laland (2006) propose a 'unified science of cultural evolution' which relies on an analogy between genes as carriers of biological characteristics and memes as carriers of culture. Compare the developmental systems approach which 'defines evolution not as change in gene frequencies but as "change in the distribution and constitution of developmental (organism-environment) systems" (Oyama 2000, p.77). The fundamental unit of evolution so conceived is the life cycle' (Thompson 2007: 188). This latter perspective enables us to make the historical nature of human beings continuous with evolutionary theory. See also Robertson 1996.
} 
afterlife or the existence of gods. ${ }^{16}$ Researchers into cognition of religion by and large have in common with Sperber the view that the transmission of ideas itself constitutes a problem, though they differ as to their commitment to massive modularity. They all argue however that the commonalities to be found in ideas about gods, ancestors, the supernatural and so on can only be a function of invariant features of human cognitive architecture - that is to say, those that are hard-wired. They include a theory of mind module, a living things module, a module that stipulates the physical properties of objects, and a module that looks for and correctly recognizes agency. ${ }^{17}$ Indeed Sperber's massive modularity argument requires that 'to an important extent, cognition enables culture through domain-specific constructive mechanisms' (Sperber 2006:447). Nothing else, he argues, can explain 'cultural stability'.

There is, however, a major problem here and it has to do with the fact that the models of evolutionary psychologists and their cognitivist followers maintain a distinction between matter and information that does not make biological sense. Here I am at one with Evan Thompson who sums up the problem as follows:

The deepest fault of the metaphor of DNA as program or information-store is that it implies a dualist framework of matter and information, one homologous to the

\footnotetext{
${ }^{16}$ For more or less radical perspectives that take this approach, see, for example, Boyer 1994 and 2001, Astuti 2001 and 2004, Tremlin 2006. Whitehouse takes a somewhat different, though not unrelated approach. He hypothesises that religious systems function according to two different modes of religious transmission - an imagistic mode and a doctrinal mode; the two modes indicate different forms of codification that correlate with distinct sets of psychological and sociopolitical features (see Whitehouse 1995, 2000 and 2004).

${ }^{17}$ Researchers differ as to whether these are all direct products of evolutionary pressures exerted on our ancestors in the Pleistocene (see Tooby and Cosmides 1992); Sperber and Boyer for example argue that beliefs in supernatural moral agents develop as by-products of innate 'pro-social cognitive mechanisms' (see Pascal Boyer's and Maurice Bloch's contributions to the critical discussion of Bering 2006, also Sperber 2006).
} 
computationalist and functionalist dualism of the mind as informational software and the brain as hardware. In both cases, processes that are intrinsically dynamic (temporally orchestrated), embodied (somatic and organismic), and embedded (necessarily situated in an environment or milieu) - whether of ontogeny, evolution, or cognition - are projected into the reified abstractions of a genetic program in the cell nucleus or a computer program in the brain (Thompson 2007: 185).

An information-processing model of mind is bound to retain distinctions between the hardware and the software, the universal and the relative, the individual and the social, the natural and the cultural. These distinctions are important to cognitivists: they provide for the idea that human biology is the domain of what is universal in human nature and that culture is the domain of what is relative. The anthropologist's job then is to interpret people's cultural representations of the world, their folk theories. This leaves explanation, science, in possession of the domain of what is natural and universal. The modularity of mind theory is a case in point. If only a certain subset of human knowledge can be properly described as 'social' or 'cultural', this implicitly isolates from contamination other knowledge processes - 'perception' for example - thus providing for a claim to an objective science of mind. This model is unconvincing because it does not allow for the fact that literally every aspect of human being, including all perceptual processes, can be shown to evince a person's history. ${ }^{18}$

\footnotetext{
${ }^{18}$ For example, ' $\ldots$. during the last trimester of pregnancy approximately 65-70 percent of human fetuses are positioned with the right ear facing out and the left ear facing in toward the mother's tissues and internal organs. As a result of this positioning, human fetuses receive different types and amounts of pre-natal experience to the right and left ears and labyrinths during late prenatal development, probably contributing to cerebral lateralisation for a variety of postnatal traits, including speech perception, language function, and limb dominance patterns, like handedness and footedness' (Lickliter 2007:14).
} 
There is, indeed, no necessity for holding to an unwieldy theory of innate massive modularity. We might, however, want to take the neuroconstructivist approach to child development proposed by the psychologist Karmiloff-Smith and her biological-connectionist colleagues who hold that development itself is the key to understanding how cognitive processes become structured in specific ways.

'... a mechanism starts out as somewhat more relevant to one kind of input over others, but it is usable ... for other types of processing too. This allows for compensatory processing and makes development channelled but far less predetermined than the nativist view. Once a domain-relevant mechanism is repeatedly used to process a certain type of input, it becomes domain-specific as a result of its developmental history' (Karmiloff-Smith 1998, referencing Elman et al 1996 and Karmiloff-Smith 1995.)

Insofar as neuroconstructivists accept the idea of innate modules, these can be nothing more than minimally specified transformational structures. Cognitive development is understood 'in terms of self-organising emergent structures arising from the complex interactions between both organism and environment' (Elman et al 1996:113). Moreover, the careful experimental work that justifies the model comes to grips with the dynamism of organism and environment. Various problems remain, however: primarily that (like Sperber's) the neuroconstructivist model is founded in a representational theory of the mind/brain and, concomitantly, in an idea of the person in which sociality is one among numerous emergent developmental structures, rather than inherent in every aspect of human being in the world; it follows that there is no awareness here that development is an historical process - that is to say, one that is embedded in historically constituted intersubjectivity.

The experimental procedures used to elicit neonates' and infants' abilities, while wonderfully convincing, tend - as do all laboratory procedures - to divert attention from the real-world conditions in which the child acquires his or her 
abilities. The neonate and infant is at any given point immersed in manifold sensations - from skin surfaces, internal organs, visceral sensations of hunger and thirst, warmth and cold, the movements of its own limbs, the different sensory modalities - and so on and so on. Moreover, these manifold sensations are like as not embedded in the waking infant's experience of being held, fed, dressed and undressed, played with, talked to, bathed, carried, caressed etc. by mother and other caretakers. It seems important to stress here the infant's whole-bodied immersion from birth (or even, it might be argued, before birth) in specific social relations - the sounds, sights, and touches of others that produce comfort or discomfort, satisfy or withhold, soothe or arouse, that are lived aspects of a specific environing world. This very observation makes evident the necessity for rendering 'developmental history' more complete by incorporating into it an analysis of the specific social relations by which it is informed and in which it inheres; for all its focus on development, the neuroconstructivist model rests on an historically specific idea of the child that takes it for granted that what is social in the child's makeup can by and large be differentiated from what is psychobiological. Thus the neuroconstructivist model is not an adequate model of development. Because it does not address how intersubjectivity informs development, it remains an artefact of experimental procedures and connectionist modelling.

Nevertheless, in the neuroconstructivist model our schemes of thought and action are self-regulating, transformational, characterised by continuing differentiation through functioning. Conscious phenomena are the artefacts of this autopoietic, developmental process. And as the dynamic product of any given human's intersubjective engagement in the environing world of people and things, cognitive 
processes that evince themselves early on in ontogeny are bound to look like modules - domain specific, fast, informationally encapsulated, mandatory. ${ }^{19}$

\section{Human sociality and theory of mind}

My concern to come to grips with the historical actuality of human beings is in part derived from the nature of anthropology as a discipline. Not only does it engage the long history of differentiation that has given rise to the contemporary variety of languages, kinship systems, political economies, cosmologies and so on, but also we anthropologists are not allowed to forget our past. There's no in-built historical amnesia in the discipline because, wherever you do your fieldwork, if you are to attain any decent understanding of the people you work with, you have to read all the work done by those who preceded you in that geographical region and, if archives exist, those too. The more fieldwork you do and the more history and ethnography you read on your region, the more you become aware that history is a dynamic process that continues feeding forward into the transforming present and that this process must lie at the heart of what it is to be human.

It follows that, in one way or another, we anthropologists have to come to grips in our ethnographies with the fact that everything about human beings evinces their history. This awareness is still held in check, however, by what appears to be an

\footnotetext{
19 " [G]iven the extraordinary complexity of the human nervous system, the infant's immersion in a world of highly differentiated sensation, and the rapid growth of interneuronal connections, this is surely ample time for ... [the] autopoietic development [of infant abilities] out of much more primitive beginnings ... as a 'self-regulating transformational system', a Piagetian scheme, even in its early stages, is going to 'look like' what cognitive psychologists call a module" (Toren 1999:).
} 
unwillingness to subject ourselves as scientists to the scrutiny we bring to bear on others. Rather we see the heralding of 'a new scientific domain.'

'The roots or foundations of human sociality [is proposed as] a coherent subject for investigation constituted by intersecting principles of different orders (ethological, psychological, sociological and cultural) that work together to produce an emergent system, a system of human sociality and social interaction' (Enfield and Levinson 2010:1).

The emphasis here is on bringing together findings from evolutionary and developmental psychology, linguistics, cognitive science, and anthropology. The analytical premises underlying the proposed new synthesis remain, however, undisturbed - principally the distinction between biology and culture, the universal and the relative, and often enough a concomitant dependence on modularity that makes it possible to distinguish social cognition from other forms of cognition. Sociality is central to an argument that provides for intersubjectivity, "enabling a brand of joint action that is truly open-ended in goals and structure [and] ... provides the building blocks for human cultural diversity" (ibid: 3). A pity then that for Enfield and Levinson the capacity for intersubjectivity itself rests on the idea of a (more or less innate) theory of mind (the so-called ToM).

As currently understood, theory of mind is a domain-specific cognitive module whose component parts are concepts about mental states; it functions to understand what others have in mind and to predict what they are going to do. Given its association with rationalism and hypothesis-testing, the use of the word 'theory' here is instructive: thus the theory of mind module is characterised as open to reorganisation in the face of disconfirming evidence. The idea of a theory of mind idea module has proved persuasive to anthropologists who have used it to argue for an idea of human nature in which people's apparently tacit understandings are effectively 
privileged by the researcher over their declared ideas (see for example Bloch 2006). Even so, those who make use of the idea vary in their commitment to its being innate, 'hard-wired' in the sense of its being well-specified at birth, though they all consider it to be at least a constraining influence on development. Thus an intermediate theoretical position is taken by Astuti et al (2004) who argue for what they call 'the constrained conceptual construction hypothesis' which

'proposes that each child must construct anew [for example, concepts of biological inheritance and natural human kinds] ... this construction ... is enabled and constrained by powerful innate domain-general learning mechanisms, such as causal analysis ... or teleological ... and essentialist modes of construal' (Astuti, Solomon and Carey 2004:15-16).

Likewise Astuti and Harris (2008) have argued that children are fundamentally rationalist in respect of their ideas concerning what happens after death and that this initial rationalism is progressively overcome, as they grow up, as a function of their taking on religious ideas held by their elders. Rationalist understandings remain cognitively available to a person, however, and the apparently paradoxical attributes of spirits may even be discussed - that they consume food but have no stomachs, for example. As Astuti and Harris recognize, however, it does not follow even from an admission that this is difficult to conceive of, that people will give up an idea that spirits consume the spirit substance of foodstuffs. I have no quarrel with Astuti and Harris's primary findings, but in my view they show only that the youngest children have not yet had experience that would allow them to find out what spirits are.

The various 'sociality theorists' whose work is brought together by Enfield and Levinson have rather different theoretical commitments. For example, Tomasello, whose earlier ground-breaking work shows that child language acquisition is a constitutive process that is demonstrably not dependent on an innate, domain- 
specific, cognitive module providing the primitive structure of a universal grammar (a language acquisition device) or even on a theory of mind module. Rather he demonstrates the rapid development of joint attention, gestural skills (especially pointing), and the ability to learn the intentional acts of others; these abilities taken together with early-developing pattern-finding skills make it possible for children

'to find patterns in the way adults use linguistic symbols across different utterances, and so to construct the grammatical (abstract) dimensions of human linguistic competence' (Tomasello 2003:4).

Likewise, in the Enfield and Levinson volume, Susan Goldin-Meadow argues convincingly that

' $[$ t]he phenomenon of language creation in deaf children tells us that an individual child can reinvent the linguistic wheel, or at least its rudimentary aspects - as long as the child can interact with humans who behave humanely' (Goldin Meadow. 2007:354).

There is a certain irony here in that Fodor's initial idea of modularity had everything to do with the idea that humans could not possibly acquire knowledge so complex and highly differentiated as language in the absence of a dedicated, innate 'language acquisition device'. The so-called LAD was among the first modules, central to the development of modularity theory throughout the 1980s and 1990s. Now that it is apparently unnecessary, we find it replaced by ToM.

Sociality theory also takes in developments in the idea of 'distributed cognition', which is influential especially in the area of education and which is associated with Lave and Wenger's (1991) work on 'situated learning' and Michael Cole's cultural historical perspective. ${ }^{20}$ The idea is more or less congruent with the neuroconstructivist model described above. Here cognitions 'are not content-free tools that are brought to bear on this or that problem; rather they emerge in a situation

${ }^{20}$ See, e.g. Kirshner and Whitson (1997). 
tackled by teams of people and the tools available to them' (Salomon 1993:xiii). Salomon is referring to the work of Cole when he argues for the view that 'the proper unit of psychological analysis should be the joint (often, but not necessarily) socially mediated activity in a cultural context' (ibid:xv, emphasis in the original). Hutchins' view would appear to be close to this when he insists that 'distributed cognition' 'is an approach to the study of all cognition' (Hutchins 2007: 376).

'Distributed cognition sees real-world cognition as a process that involves the interaction of the consequences of past experience (for individual, group, and material world) with the affordances of the present. In this sense, culture is built into the distributed cognition perspective as at least a context for cognition' (ibid: 377 ).

This is all very well, but for all the expressed concern for real world processes, the underlying dualist assumptions remain unaddressed by either Cole or Hutchins and the model remains, therefore, computational and ahistorical. Oddly so, given Cole's long insistence on the necessity for incorporating an historical perspective into cognition. The problem lies, I think, in the very way that his 'cultural historical activity-based approach to cognition leads one to think about the distribution of cognition among people, cultural artefacts, and time' (Cole 1993:22). By contrast, the unified model of human being that I argued for above makes it obvious that, by virtue of evolution, we humans, like other living things, inhere in the world. From which it follows that inevitably we make use of its manifold aspects in making sense of it intersubjectively over time. ${ }^{21}$ But there is no mystery here, I think.

I have a good deal of sympathy with the idea of sociality as a domain of investigation, but only if it is understood that neurobiological, psychological and sociocultural data give us access not to different 'levels' of integration (and thus of

${ }^{21}$ For intersubjectivity, see Trevarthen 1988 and compare contributions to Bråten 1998 (especially Kuhl, Meltzoff and Moore, and Trevarthen) and Rumsay 2003. 
explanation) but to aspects of one and the same phenomenon. I argue that we cannot build genuinely explanatory psychological or biological models without reference (at least in principle) to the fact that our biology and psychology are embedded in a long history of social relations, whose analysis is going to be germane to any biological and psychological model that purports to be explanatory. Further our ethnographic analyses of social relations are essential for understanding the historical specificity of intersubjectivity in any given case and thus for showing how learning processes are themselves structured according to certain ideas about what humans are and can be.

\section{Embodiment and neurophenomenology}

Anthropologists may be much encouraged by the publication of Evan Thompson's brilliant Mind in Life in which he argues for a

$$
\begin{aligned}
& \text { "neurophenomenology ... [whose] aim is to incorporate phenomenological } \\
& \text { investigations of experience into neuroscientific research on consciousness. } \\
& \text { Neurophenomenology focuses especially on the temporal dynamics of conscious } \\
& \text { experience and brain activity ....' Thompson 2007:312. }
\end{aligned}
$$

From my point of view, the great thing about a neurophenomenological model of mind is that it is open to coming to grips with human historicity and precisely for this reason, wants anthropological input.

"The idea that phenomenology could stand in an explanatory relation to biology ... will sound odd to many readers. What could phenomenology possibly explain in this domain? The answer is nothing less than how certain biological processes are also realizations of selfhood and subjectivity...." Thompson 2007, p.358

Of course, most writers (even Evan Thompson) continue to think that the problem is to build culture into their models, but this re-introduces the biology-culture distinction that has for so long interfered with our ability to produce a unified model of human being. As I have suggested, however, we do better to analyse ontogeny as an historical 
process showing, for example, how language acquisition engages social relations that are themselves historically structured. Here Tomasello's wonderfully convincing account of the fundamentals of language acquisition becomes useful again, because it is easy enough to show how the process is intrinsically historical (Tomasello 2003).

I have to insist here that intersubjectivity should not be confused with 'social interaction'. Nor should the process of making sense intersubjectively of the world be confused with 'social construction'. Where learning is understood as a microhistorical process, the peopled world, for all it operates according to its own dynamics, cannot ever be understood independently of the history of the knowing subject. In other words, the validity of a given scientific study, is itself an historically constituted judgement - which is not to say that scientific studies may not be arguably more, or less, valid. The point is that if our categories are to work analytically, they have to be rendered such by means of ethnographic analysis. They are not to be taken for granted, for they too warrant investigation - 'society', 'individual', 'biology', 'culture', 'self', 'mind' and so on are cases in point.

My argument here is, firstly, that because temporality inheres in consciousness, learning instantiates the microhistorical processes that over time give rise to the phenomena of consciousness as always open to further differentiation. Secondly, that because transformation and continuity are aspects of the microhistorical process of human autopoiesis, ethnographic analyses of ontogeny can provide a way in to theorising the mutual connections between human evolution, history (a regional history, for example), contemporary lives, consciousness and the neurobiology of consciousness. ${ }^{22}$ Moreover it is important for us as anthropologists to understand that the peopled world provides for all our historically constituted 22 For developments in the anthropology of consciousness, see Throop and Laughlin 2007. 
descriptions of it, such that these always and inevitably partial descriptions are rendered objective in different ways. ${ }^{23}$

Ethnographic studies of how children make sense of the conditions in the world created for them by adults can contribute to the dynamic systems perspective on human development over time as an autopoietic and historical process - one that grounds the entire spectrum of individual difference (within and across regions of the world) in the way that our biology provides for sociality, specifically for empathy and intersubjectivity, as the bedrock condition of human being. Further the details of ethnographic studies of ontogeny as an historical process feed directly into the argument that the development of the neural processes that characterize human conceptual development is an emergent aspect of the functioning of an embodied nervous system for which intersubjectivity is a necessary condition.

${ }^{23}$ See, e.g., Toren 2007 and 2009. 


\section{References}

Astuti, Rita 'Are we all natural dualists? A cognitive developmental approach'. Journal of the Royal Anthropological Institute (NS) 7:429-447. 2001.

- Astuti, Rita 'What happens after death?'. In Rita Astuti, Jonathan Parry and Charles Stafford eds. Questions of Anthropology, London Berg 2007.

Astuti, Rita, Greg E.A. Solomon and Susan Carey. Constraints on Conceptual Development. A Case Study of Folkbiological and Folksociological Knowledge in Madagascar. Oxford, Blackwell 2004.

Astuti, Rita and Paul Harris.' Understanding mortality and the life of the ancestors'. Cognitive Science 32: 713-740, 2008.

Bering, Jesse M. 'The folk psychology of souls'. Behavioural and Brain Sciences 29: 453-458, 2006

Bloch, Maurice. L'anthropologie cognitive à l'épreuve du terrain. L'example de la théorie de l'esprit. Collège de France/Fayard, 2006.

Boyer, Pascal. The naturalness of religious ideas: a cognitive theory of religion. Berkeley, University of California Press. 1994.

- Religion Explained: The Evolutionary Origins of Religious Thought, New York. Basic Books 2001.

Bråten, Stein (ed). Intersubjective Communication and Emotion in Early Ontogeny, Cambridge University Press, 1998.

Cole, Michael. 'A cultural historical approach to distributed cognition'. In Salomon, Gavriel. Ed. Distributed Cognitions : Psychological and Educational Considerations. Cambridge University Press, 1993.

- Cultural Psychology: A Once and Future Discipline. Harvard University Press. 1996.

Csibra, Gergely and György Gergely. 'Social learning and social cognition: the case for pedagogy', in Y. Munakata and M.H. Johnson (eds) Processes of Change in Brain and Cognitive Development, Attention and Performance, XXI:249274, Oxford, Oxford University Press, 2006.

Csordas, Thomas J. 1990. 'Embodiment as a paradigm for anthropology', Ethos, 18, $5-47$.

Damasio, Antonio. The Feeling of What Happens: Body, Emotion and the Making of Consciousness, London: William Heinemann. 1999.

D'Andrade, Roy. The Development of Cognitive Anthropology, Cambridge University Press 1995.

Elman, Jeffry L., Elizabeth A. Bates, Mark H. Johnson, Annette Karmiloff-Smith, Domenico Parisi, Kim Plunkett. Rethinking Innateness. A Connectionist Perspective on Development. Cambridge Mass., MIT Press, 1996.

Enfield, N.J. and Stephen C. Levinson. Eds. Roots of Human Sociality. Culture, Cognition and Interaction. Berg. 2006.

Fodor, Jerry A. The Modularity of Mind, The MIT Press, 1983.

'The trouble with psychological Darwinism', London Review of Books, Vol. 20, No. 2, 11-13, 1988.

Goldin-Meadow, Susan. 'Meeting other minds through gesture: how children use their hands to reinvent language and distribute cognition.' In N.J. Enfield and Stephen C. Levinson, eds. Roots of Human Sociality. Culture, Cognition and Interaction. Berg. 2006.

Hacking, Ian The Social Construction of What?, Harvard University Press, 1999. 
Hirschfeld, Lawrence A. and Susan A. Gelman (eds) Mapping the Mind: Domain Specificity in Cognition and Culture, Cambridge University Press 1994.

Hutchins, Edwin. 'The distributed cognition perspective on human interaction'. In Enfield, N.J. and Stephen C. Levinson. Eds. Roots of Human Sociality. Culture, Cognition and Interaction. Berg. 2006.

Ingold, Tim. 'The social child'. In Alan Fogel, Barbara King and Stuart Shanker, Eds. Human Development in the Twenty-First Century. A Dynamic Systems Approach to the Life Sciences, Cambridge University Press, 2007.

Karmiloff-Smith, Annette. 'Annotation: the extraordinary cognitive journey from foetus through infancy', Journal of Child Psychology and Psychiatry, 36, 8, 1293-1313, 1995.

- 'Development itself is the key to understanding developmental disorders', Trends in Cognitive Sciences, 2:389-398. 1998.

Kessen, W. 1983. 'The child and other cultural inventions' in F.S. Kessel \& A.W. Siegel (eds) The Child and Other Cultural Inventions, Praeger Publishers.

Kirshner, David and James A. Whitson Situated Cognition: Social, Semiotic and Psychological Perspectives. New Jersey. Lawrence Erlbaum. 1997.

Lave, Jean and Etienne Wenger, Situated Learning, Cambridge University Press, 1991.

LeVine, Robert A. Psychological Anthropology: A Reader on Self in Culture. Oxford. Wiley-Blackwell, 2010.

Lewis, Marc. 'Emotional self-organization at three time scales'. In M.D. Lewis and I.Granic Emotion, Development and Self-Organization: Dynamic Systems Approaches to Emotional Development. Cambridge University Press, 2000.

- Bridging emotion theory and neurobiology through dynamic systems modeling. Behavioural and Brain Sciences 28: 169-194. 2005.

Lickliter, Robert. Developmental Dynamics. The new view from the life sciences. In Alan Fogel, Barbara King and Stuart Shanker, Eds. Human Development in the TwentyFirst Century. A Dynamic Systems Approach to the Life Sciences, Cambridge University Press, 2007.

Mesoudi, Alex, Andrew Whiten and Kevin N. Laland. 'Towards a unified science of cultural evolution'. Behavioural and Brain Sciences 29: 329-383, 2006.

Nussbaum, Martha C. Upheavals of thought : the intelligence of emotions Cambridge; New York : Cambridge University Press, 2001.

Oyama, S. Evolution's Eye: A System's View of the Biology-Culture Divide. Durham, NC, Duke University Press. 2000.

Piaget, Jean. Structuralism, London, Routledge \& Kegan Paul, 1971 (orig. 1969).

Robertson, A.F. The development of meaning: Ontogeny and culture. Journal of the Royal Anthropological Institute (N.S.) 2, 591-610. 1996.

Rumsay, Alan. 'Language desire and the ontogenesis of intersubjectivity'. Language and Communication 23(2) 169-187 2003.

Salomon, Gavriel. Ed. Distributed Cognitions : Psychological and Educational Considerations. Cambridge.Cambridge University Press, 1996.

Schwartz, Theodore, Geoffrey M. White and Catherine A. Lutz. New Directions in Psychological Anthropology, Cambridge University Press. 1992.

Shore, Bradd. Culture in Mind: Cognition, culture and the problem of meaning, Oxford: O.U.P., 1996.

Shweder, R.A. Thinking Through Cultures. Expeditions in Cultural Psychology, Harvard U.P. 1991. 
Spelke, Elisabeth. 'Infant cognition'. In Robert A. Wilson and Frank C. Keil. The MIT Encyclopedia of the Cogntive Sciences. Cambrdige Mass \& London. MIT Press. 1999.

Sperber, Dan. 'The modularity of thought and the epidemiology of representations'. In Hirschfeld, Lawrence A. and Susan A. Gelman (eds) Mapping the Mind: Domain Specificity in Cognition and Culture, Cambridge University Press 1994.

- Explaining Culture: A Naturalistic Approach. Oxford. Wiley-Blackwell. 1996.

- 'Why a deep understanding of cultural evolution is incompatible with shallow psychology'. In N.J. Enfield and Stephen C. Levinson. Eds. Roots of Human Sociality. Culture, Cognition and Interaction. Berg. 2006.

Strauss, Claudia and Naomi Quinn. A Cognitive Theory of Cultural Meaning, Cambridge University Press. 1997.

Thompson, Evan. Mind in Life. Biology, Phenomenology and the Sciences of Mind. Cambridge, Mass. The Belknap Press of Harvard University Press. 2007.

Throop, Jason C. and Charles D. Laughlin. 'Anthropology of consciousness'. In Philip David Zelazo, Morris Moscovitch, and Evan Thompson (eds.), The Cambridge Handbook of Consciousness. Cambridge University Press, 2007.

Tomasello, Michael. Constructing a Language, Harvard University Press, 2003

Tooby, John and Leda Cosmides, 'The psychological foundations of culture' in J.H.Barkow, L.Cosmides and J.Tooby (eds) The Adapted Mind: Evolutionary Psychology and the Generation of Culture, Oxford University Press 1992.

Toren, Christina. Making Sense of Hierarchy. Cognition as social process in Fiji, London School of Economics, Monographs in Social Anthropology, 61, London, The Athlone Press, 1990.

- Mind, Materiality and History: Explorations in Fijian Ethnography, Routledge 1999.

- Anthropology as the whole science of what it is to be human. In R. Fox and B. King (eds) Anthropology Beyond Culture, London, Berg, pp 105-124, 2002.

- How do we know what is true? The case of mana in Fiji. For Questions of Anthropology. Eds. R.Astuti, J. Parry and C. Stafford. Oxford: Berg. 2007.

- An anthropology of human development - what difference does it make? In Alan Fogel, Barbara King and Stuart Shanker, Eds. Human Development in the Twenty-First Century. A Dynamic Systems Approach to the Life Sciences, Cambridge University Press, 2007.

Toren, Christina and Joâo de Pina-Cabral. Eds. What is Happening to Epistemology? Social Analysis. Volume 53, Issue 2, 2009.

Tremlin, Todd. Minds and Gods, Oxford, Oxford University Press, .2006

Trevarthen, Colwyn. 'Universal cooperative motives: how infants come to know the language and culture of their parents' in G.Jahoda and I.M. Lewis (eds) Acquiring Culture: Cross-cultural Studies in Child Development, London, Croom Helm, 1988.

Whitehouse, Harvey. Arguments and Icons Divergent Modes of Religiosity. Oxford. Oxford University Press. 2000.

- Modes of Religiosity: A Cognitive Theory of Religious Transmission. Altamira Press 2004. 